\title{
Beaver (Castor fiber) activity and spatial movement in response to light and weather conditions
}

\author{
Laura Bartra Cabré $^{1,2} \cdot$ Martin Mayer $^{1,3} \cdot$ Sam Steyaert ${ }^{1,4} \cdot$ Frank Rosell $^{1}$
}

Received: 15 May 2019 / Accepted: 1 April 2020 / Published online: 23 April 2020

(c) The Author(s) 2020

\begin{abstract}
Animal behaviour can affect individual fitness and is influenced by exogenous and endogenous factors. Here, we investigated how light (daylight length and moonlight), weather (precipitation and temperature), age, sex and social status affected activity and movement of a semiaquatic mammal, the Eurasian beaver (Castor fiber), using GPS relocation data from 47 individuals in south-eastern Norway. Independent of daylight length, beavers had a mean daily activity time of 9:42 $\mathrm{h}$ and reduced their activity periods when they were older, most likely due to senescence. In line with this, older individuals also spent less time in water and moved shorter distances. Furthermore, beavers reduced their activity periods in drier weather conditions and spent less time on land during brighter nights and drier conditions, indicating a predation risk avoidance strategy. Individuals spent less time in the water during the colder parts of the year and moved shorter distances with decreasing temperature, suggesting thermal constraints. Our study adds to the increasing amount of evidence that animal behaviour is modulated by various endogenous and exogenous factors, and that weather conditions can affect their behaviour. It remains to be tested, however, how climate variability together with hunting and predation pressure affect space use and demography in species such as the Eurasian beaver.
\end{abstract}

Keywords Activity patterns $\cdot$ Daylength $\cdot$ Moonlight $\cdot$ Movement ecology $\cdot$ Space use

Handling editor: Raquel Monclús.

Electronic supplementary material The online version of this article (https://doi.org/10.1007/s42991-020-00029-7) contains supplementary material, which is available to authorized users.

Frank Rosell

frank.rosell@usn.no

1 Faculty of Technology, Natural Sciences, and Maritime Sciences, Department of Natural Sciences and Environmental Health, University of South-Eastern Norway, 3800 Bø i Telemark, Norway

2 Faculty of Biology, University of Barcelona, 08028 Barcelona, Spain

3 Department of Bioscience, Aarhus University, 8000 Aarhus, Denmark

4 Faculty of Biosciences and Aquaculture, Nord University, 7711 Steinkjer, Norway

\section{Introduction}

Movement behaviour of animals can affect their fitness and is influenced by a wide range of exogenous (e.g. daylight length, weather and moon illumination) and endogenous (e.g. sex, age and social status) factors (Nathan et al. 2008). Daylight length (hereafter 'daylength') is an important ecological constraint for many animals since it delineates the period within which individuals perform their essential activities (Dunbar et al. 2009), and seasonal variation in day length can limit available time for foraging or other activities (Hill et al. 2003). Individuals can adjust their behaviour due to energetic constrains (Hut et al. 2012) or in response to variation in predation risk, e.g. nocturnal species can alter their behaviour with changing moonlight conditions (Brown and Kotler 2004; Julien-Laferrière 1997). Huck et al. (2017) suggested that the activity of different species of ocelot's (Leopardus pardalis) prey depends on preys' night vision because species with good night vision will be more likely to detect predators during night-time, whereas species with poor night vision might experience higher predation risk. For example, owl monkeys (Aotus azarai) increased 
nocturnal activity with increasing moonlight, possibly due to the absence of a tapetum lucidum, an intraocular tissue that stimulate the reception of light that reaches the retina (Ollivier et al. 2004) which renders activity in total darkness more difficult (Fernandez-Duqueò 2003). In contrast, kangaroo rats (Dipodomys merriami, also lacking tapetum lucidum) became more crepuscular during full moon nights to avoid predation (Daly et al. 1992). In addition, human activity and hunting can alter activity patterns of animals across taxa and habitats, and can lead to increased nocturnality (Gaynor et al. 2018; Hertel et al. 2016).

Weather conditions can also affect behaviour (Burles et al. 2009), activity (Bartness and Albers, 2000; Vieira et al. 2009), and movement patterns (Stokes et al. 2001; Togunov et al. 2017) of many mammals. Being active at suitable times may help individuals to avoid excessive loss of energy due to body temperature regulation (Vickery and Bider 1981), which can be important for foraging efficiency (Caraco et al. 1990). For example, precipitation might alter animal activity, as woodland jumping mice (Napaeozapus insignis) and Southern red-backed voles (Myodes gapperi) activity increased during rainy nights, possibly because the noise created by rainfall and washed scent traces led to decreased predation risk (Vickery and Bider, 1981). European badgers (Meles meles) were more likely to be live-trap captured during rainy weather, suggesting increased activity (Martin et al. 2017), likely due to an increased availability of earthworms and/or because of a low perceived predation risk caused by the washed scent traces of humans around their setts. The efficiency of predators can differ with different intensities of precipitation. For example, it is very difficult for dogs (Canis lupus familiaris) to find game when it is raining hard, but if the ground surface is damp, the dog smells scents easier (Conover 2007; Syrotuck 2000), as higher humidity increases the odorants evaporating from the surface (Rosell 2018).

In addition to environmental factors, demographic factors can affect the animal activity and movement as well. For example, older individuals of northern fur seals (Callorhinus ursinus) have a higher site fidelity than young ones, which is probably related to sexual maturation and experience in returning to the same site (Baker et al. 1995). In brown bears (Ursus arctos), females with cubs-of-the-year can limit their movements during the mating season to reduce infanticide risk (Steyaert et al. 2014). Variation by sex has also been observed in common seals (Phoca vitulina) activity patterns, especially because of the different seasonal demands for both sexes related to parental care (Thompson et al. 1989). However, for most monogamous mammals, movement patterns do not appear to differ much between males and females (Kleiman 1977). Also brown bear activity patterns showed to differ with age, with adults being more active during the night to avoid human encounters, suggesting that experience through learning is more relevant than genetic factors (Kaczensky et al. 2006). Also, a decline in activity and movement has been attributed to senescence effects in a range of animals (Ingram 2000), probably because of habituation to their environment, and because dopamine (a neurotransmitter responsible for locomotion motivation) decreases with age.

Both the Eurasian beaver (Castor fiber) and the North American beaver (C. canadensis) are large and monogamous rodents (Svendsen 1980; Wilsson 1971). They are semi-aquatic, being on land mostly for foraging and in water mostly to travel (Sharpe and Rosell 2003). Beavers live in single-family groups consisting of the breeding pair (hereafter 'dominants') and their offspring, here categorized into kits ( $<1$-year-old offspring) and $\geq 1$-year-old offspring from previous years (hereafter 'subordinates') (Bradt 1938; Campbell et al. 2005). The dominant pair advertises territory occupancy by constructing scent mounds on land close to the territory border (Rosell and Nolet 1997). Beavers are mainly nocturnal (Tevis 1950; Wilsson 1971), typically emerging from their lodge at dusk and returning at dawn (Mott et al. 2011; Rosell et al. 2006). They feed on deciduous tree parts and herbs on land (Wilsson 1971), but also on aquatic vegetation (Müller-Schwarze and Schulte 1999). During autumn, beavers build a food cache in front of their lodge (which serves as shelter), to provide a food stock for the winter (Wilsson 1971). Reproduction takes place between January and February, with offspring being born around May (Wilsson 1971). Previous studies in the Netherlands and Belgium in a virtually predator free-landscape found that beavers not only adjust their activity patterns with respect to daylength (Nolet and Rosell 1994), but also to moonlight. There, beavers were more active in brighter nights, as higher foraging success might compensate for higher predation risk perception (Swinnen et al. 2015). Further, the beavers' physiology enables them to adapt well to cold temperatures (MacArthur 1989), with the beaver tail regulating heat loss (Steen and Steen 1965). Low water temperatures $\left(<10^{\circ} \mathrm{C}\right)$, however, lead to increased thermoregulatory heat production costs (MacArthur and Dyck 1990) and reduced beaver activity (Nolet and Rosell 1994), confining spatial movements to the lodge surroundings (Lancia et al. 1982). The potential daily swimming time is dependent on water temperature. In summer, conditions are much more favourable for swimming larger distances due to decreased energy loss (Nolet and Rosell 1994). Other studies have explored the effect of precipitation on Eurasian beaver body weight (Campbell et al. 2013) and population dynamics (Campbell et al. 2012), but little is known about the effect of weather on movement and activity patterns. In addition, subordinate beavers conduct more extra-territorial forays compared to the dominant territory owners (Mayer et al. 2017b), and older beavers spend comparatively more time on land, either due to increased experience or senescence (Graf et al. 2016). 
Here, we investigated how light conditions (daylength and moonlight), weather (temperature and precipitation) and biological factors (age, sex and social status) influenced activity periods and spatial movement patterns of Eurasian beavers in a population in south-eastern Norway. We hypothesized that beaver activity period, distance moved, and the proportion of time spent in water or on land, would depend on light conditions (I), air temperature (II), precipitation (III), and demographic factors such as age, sex, and social status (IV). We predicted that beavers would mainly be active during nocturnal hours (I.a.), emerging from the lodge at dusk and return at dawn, and that they would be more active (I.b.), and spend more time in water (I.c.) during brighter moon nights, due to reduced vision in the darker hours. We predicted that beavers would be less active (II.a.) and spend less time in the water (II.b.) during colder days, to reduce energy loss, and that beavers would be more active (III.a.) and spend more time on land (III.b.) with increasing precipitation, as a result of reduced predation and hunting risk. Finally, we predicted that sex and status would not influence temporal or spatial activity patterns, but older beavers would be less active (IV.a.), travel shorter distances (IV.b.), and spend less time in water (IV.c.), due to increased experience or because of senescence.

\section{Material and methods}

\section{Study area and animals}

The study area consisted of three interconnected rivers: Straumen $\left(59^{\circ} 29^{\prime} \mathrm{N}, 09^{\circ} 153^{\prime} \mathrm{E}\right)$, Gvarv $\left(59^{\circ} 386^{\prime} \mathrm{N}\right.$, $\left.09^{\circ} 179^{\prime} \mathrm{E}\right)$, and Saua $\left(59^{\circ} 444^{\prime} \mathrm{N}, 09^{\circ} 307^{\prime} \mathrm{E}\right)$ in Telemark county, south-eastern Norway, where daylength varies from near-polar night to near midnight sun. All three rivers flow through agricultural and riparian mixed forest landscapes (Steyaert et al. 2015), and empty into Lake Norsjø. Beavers do not build dams in the study rivers, as the rivers are sufficiently wide and deep (Hartman and Törnlöv 2006). The riverbank consisted mostly of herbaceous and woody vegetation, such as grey alder (Alnus incana), being the dominant species, willow (Salix spp.), and bird cherry (Prunus padus) (Haarberg and Rosell 2006). The climate in the area is cool continental and wet, with mean temperatures during the study period of $8.5 \pm 5.5{ }^{\circ} \mathrm{C}$ from March to June (with June being the month with the highest average temperature, $14.7^{\circ} \mathrm{C}$ ) and $8.7 \pm 6.0^{\circ} \mathrm{C}$ from August to November (with August being the month with the highest average temperature, $15.1{ }^{\circ} \mathrm{C}$ ), and a mean precipitation of $58 \pm 26 \mathrm{~mm}$ (mm) from March to June and $88 \pm 24 \mathrm{~mm}$ from August to November (Norwegian Meteorological Institute (MET) 2017). The rivers are usually not covered with ice during winters (Campbell et al. 2012). Beaver hunting and trapping is allowed from October 1 to April 30 (Rosell and Parker 1995). Hunting pressure was moderate, with 54 (12\%) of 454 live-captured individuals being hunter harvested between 1998 and 2016 (Mayer 2017). Predation pressure was considered to be low or absent because wolves (C. lupus) and brown bears are absent in the study area, and Eurasian lynx (Lynx lynx) occur at low densities. However, Rosell and Sanda (2006) showed that beavers avoided experimental scent mounds supplied with faeces from both wolves and lynx. Further, red foxes (Vulpes vulpes) were present, and are reported to occasionally kill beaver kits (Kile et al. 1996).

Eurasian beavers in our study area have been part of a long-term, individual-based monitoring program since 1998 (Campbell et al. 2005, 2012). Animals were captured and monitored every year during spring (March to June) and fall (August to November) using a motorboat and handheld net (Rosell and Hovde 2001). The sex was determined based on the colour and viscosity of the anal gland secretion (Rosell and Sun 1999). Age was determined based on body mass at first capture (Mayer et al. 2017c; Rosell et al. 2010). For beavers being first captured as an adult, we assigned an estimated minimum age based on body mass (Campbell et al. 2012). Individuals were classified as minimum 2 years old when they had a mass $\geq 17 \mathrm{~kg} \mathrm{(kg)} \mathrm{and} \leq 19.5 \mathrm{~kg}$, or as minimum three years when $>19.5 \mathrm{~kg}$ at the time of the first capture. For individual identification, all beavers were tagged with a microchip and a unique ear tag, and assigned to a social status (subordinate or dominant) (Campbell et al. 2012).

We GPS-tagged 47 individuals from 22 different territories during spring (March to June) and fall (August to November) from 2009 to 2016. GPS receivers (model G1G 134A; Sirtrack, Havelock North, New Zealand or TGB317/315GX; Telenax, Playa del Carmen, Mexico) were programmed to take one GPS position every $15 \mathrm{~min}$ (min) from 19:00 to 7:00 h (hrs) and were set to sleep (not recording locations) during the remaining period of time when beavers are generally not active (Sharpe and Rosell 2003). Tags, consisting of a GPS receiver and a VHF transmitter (Reptile glue-on, series R1910; Advanced Telemetry Systems, Isanti, MN, USA) were attached on the fur of the lower back, ca. $15 \mathrm{~cm}$ above the tail end using a two-component epoxy resin (Graf et al. 2016). We recaptured the beavers after one to three weeks and removed the tag from the fur using a scalpel.

\section{Ethical statement}

All trapping and handling procedures were approved by the Norwegian Experimental Animal Board (FOTS ID 742, ID $2170,2579,4384,6282,8687)$ and the Norwegian Directorate for Nature Management (2008/14367 ART-VI-ID, archive code 444.5, 446.15/3, 14415), which also granted 
permission to conduct fieldwork in the study area. Our study met the American Society of Mammalogists (ASM) Guidelines (Sikes et al. 2016). None of the beavers were injured during capture and handling, and all were successfully released at the site of capture after handling. We observed no subsequent long-term effects of capture and tagging.

\section{Data preparation}

We used the first GPS position in the evening and the last GPS position the following morning to determine the start and end of the activity time (time beavers spent outside the lodge) during each day, since the GPSs do not record positions when underground (Schlippe Justicia et al. 2018). Each GPS position was assigned to being on land or in water using digital topographical maps in ArcMap 10.1 (Esri, Redlands, CA, USA) to calculate the proportion of observations per night spent in each location. This measure must be treated with caution because beavers typically stay close $(<20 \mathrm{~m}$ (m)) to the shore both when in water and on land (Graf et al. 2016), and the mean GPS location error was $15 \mathrm{~m}$ (Schlippe Justicia et al. 2018). Spatial data of water bodies was obtained from the Norwegian map database (Norwegian Mapping Authority (Kartverket) 2017). We might have incorrectly assigned a number of GPS positions to land or water due to GPS inaccuracy (Schlippe Justicia et al. 2018), erroneous maps and varying water levels. However, we assume that this was a systematic error (we incorrectly assigned a similar proportion of GPS positions to land and water). To determine the distance covered by a beaver during each activity period (night), we calculated the straightline distance between consecutive GPS positions, defined as 'distance moved' ( $\mathrm{m} / 15 \mathrm{~min})$, and took the average of all straight-line distances separately for each night (i.e., average movement speed per night).

We obtained sunrise and sunset time data using the $\mathrm{R}$ package 'StreamMetabolism' (Sefick Jr 2016), and lunar data (illumination fraction (from 0 , no illumination, to 1 , full moon) every hour, not taking into account cloud cover) from the R package 'oce' (Kelley and Richards 2019) using the function 'moonAngle' with Oslo longitude and latitude (Lat: 59.4, Long: 9.3, ca. $105 \mathrm{~km}$ from the centre of our study area). Weather data was obtained from the Meteorological Institute of Norway (MET Norway, URL: https://www.met. no/), from Gvarv meteorological station. This data included daily mean, minimum, and maximum temperatures $\left({ }^{\circ} \mathrm{C}\right)$, and cumulative precipitation $(\mathrm{mm})$. The temperature measures were correlated with each other $(r>0.6)$ (Zuur et al. 2010). Therefore, we only included daily mean temperature in our analysis.

\section{Statistical analyses}

To investigate whether beavers are nocturnal (to test prediction I.a.), i.e. emerging from the lodge around sunset and returning around sunrise, we used a linear mixed-effect regression model (LMM) using the 'Ime4' package in $\mathrm{R}$ (Bates et al. 2015). We divided the data into two periods, spring (March to June; increasing daylength) and fall (August to October; decreasing daylength) and obtained the first (start) and last (end) location each night for each beaver for both periods. We calculated the time difference (in hrs, dependent variable) between the activity start and sunset, and the activity end and sunrise, and investigated if this time difference changed over the year (Julian day, fixed effect). We ran four models to assess potential seasonal differences in activity: differences of time at (1) the start and (2) the end of the activity during spring, and at (3) the start and (4) the end of the activity during fall. Beaver ID (repeated measures of individuals) was included as random intercept to control for non-independence of the data. If beaver activity strictly followed sunrise and sunset, the deviation from the activity start and end is expected to be relatively constant around 0 throughout the year. If beavers do not follow daylength, we expect systematic deviations in activity start and end over the time of the year compared to sunset and sunrise. Negative deviations would indicate that beavers start their activity before sunset and/or finish their activity after sunrise and positive deviations would indicate that beavers start their activity after sunset and/or finish their activity before sunrise.

We analysed which factors affected the daily activity period (defined as the time from the first to the last GPS position in hrs., dependent variable, to test predictions I.b., II.a., III.a. and IV.a.) using a LMM (Table 1). We included age, sex, social status, the quadratic function of Julian day, temperature, precipitation, and moon illumination as fixed effects, and beaver ID was included as random intercept.

To investigate spatial movement patterns, we analysed (as dependent variables) (1) proportion of time spent in water (in water $=1$ versus on land $=0$, to test predictions I.c., II.b., III.b. and IV.c.) using generalized linear mixed models with a Bernoulli distribution and a logit link, and (2) average distance moved (average $\mathrm{m} / 15 \mathrm{~min}$ per night, to test predictions I.b., II.a., III.a., IV.a. and IV.b.) using LMMs (Table 1). In both analyses, we included temperature, precipitation, moonlight, the quadratic function of Julian day, sex, age and social status as fixed effects and beaver ID as random intercept. We scaled and centred all numeric fixed effects to avoid convergence issues and to be able to compare their relative effect sizes. We tested for correlations between the fixed effects (Zuur et al. 2010), but we did not observe a correlation between the variables (all $r<0.6$ ). For both the analyses of activity period and spatial movement patterns, 
Table 1 Overview of statistical analyses and models showing the dependent variables and fixed effects, the number of observations for each analysis $(N)$, the model distribution and pseudo $R$-squared [marginal ${ }^{\mathrm{a}}(\mathrm{m})$ and conditional $^{\mathrm{b}}$ (c) coefficients]

\begin{tabular}{|c|c|c|c|c|c|}
\hline Analysis (dependent variable) & Fixed effects & $N$ & Distribution & $R_{\mathrm{m}}^{2}$ & $R_{\mathrm{c}}^{2}$ \\
\hline Activity period (h) & $\begin{array}{l}\text { Age }+ \text { moon illumination }+ \text { precipitation }+ \text { Julian day }+ \text { Julian } \\
\text { day }^{2}+\text { sex }+ \text { social status }+ \text { temperature }\end{array}$ & 658 & Gaussian & 0.103 & 0.559 \\
\hline In water (yes/no) & $\begin{array}{l}\text { Age }+ \text { moon illumination }+ \text { Julian day }+ \text { Julian } \text { day }^{2}+\text { precipita- } \\
\text { tion }+ \text { sex }+ \text { social status }+ \text { temperature }\end{array}$ & 18,652 & Bernoulli & 0.011 & 0.056 \\
\hline Average distance moved $(\mathrm{m} / 15 \mathrm{~min} /$ night $)$ & $\begin{array}{l}\text { Age }+ \text { moon illumination }+ \text { Julian day }+\mathrm{Julian} \mathrm{day}^{2}+\text { precipita- } \\
\text { tion }+ \text { sex }+ \text { social status }+ \text { temperature }\end{array}$ & 695 & Gaussian & 0.153 & 0.467 \\
\hline
\end{tabular}

Beaver ID was included as a random effect in all analyses

$h$ hours

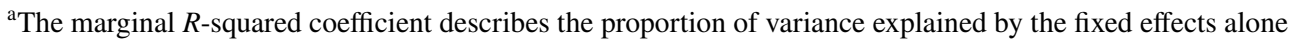

${ }^{\mathrm{b}}$ The conditional $R$-squared coefficient describes the proportion of variance explained by both the fixed and the dependent variable

we created candidate models with all combinations of the single fixed effects without interactions.

Model selection was based on Akaike's Information Criterion (AIC) (Burnham et al. 2011), and was carried out using the R package 'MuMIn' (MuMIn). If $\triangle \mathrm{AIC}$ was $<2$ in two or more of the top-ranked models (see supplementary table SD1), we performed model averaging (Anderson 2007). Parameters that included zero within their 95\% CI were considered uninformative (Arnold 2010). We validated all model assumptions visually by plotting standardized residuals against fitted values (Zuur et al. 2010), which indicated no clear heteroskedasticity or deviations from normality in our models. We conducted all analyses in R 3.6.0 (R Core Team 2013).

\section{Results}

We obtained 18,652 GPS positions of 47 beavers [11 tagged twice, 4 tagged 3 times; 25 males, 22 females; 42 dominants (5 of them subordinates the first time captured), 5 subordinates] during 658 individual nights (total of single nights during which the animals were GPS's monitored), on average $337 \pm 157$ (mean \pm SD) GPS positions, and $10 \pm 4$ activity periods (nights) per individual.

The average start of the activity time was 20:08 $\pm 0: 40 \mathrm{~h}$, and the average end of the activity was $6: 50 \pm 0: 44 \mathrm{~h}$. Comparing between seasons, the mean starting time in spring $(n=191)$ was $20: 04 \pm 0: 36 \mathrm{~h}$ (average sunset time: 20:50 $\pm 0: 39 \mathrm{~h})$ and 20:10 $\pm 0: 43 \mathrm{~h}$ in fall $(n=227$, average sunset time: 19:04 $\pm 1: 17 \mathrm{~h})$. The mean end time was $6: 39 \pm 0: 35 \mathrm{~h}$ in spring (average sunrise time: $5: 57 \pm 0: 44 \mathrm{~h}$ ) and 6:59 $\pm 0: 36 \mathrm{~h}$ in fall (average sunrise time: 7:24 $\pm 1: 03 \mathrm{~h}$ ) (Fig. 1). During both spring and fall, the start and end time of beaver activity deviated significantly from sunrise and sunset, respectively (Table 2). Beavers tended to become active after sunset and returned to the lodge before sunrise

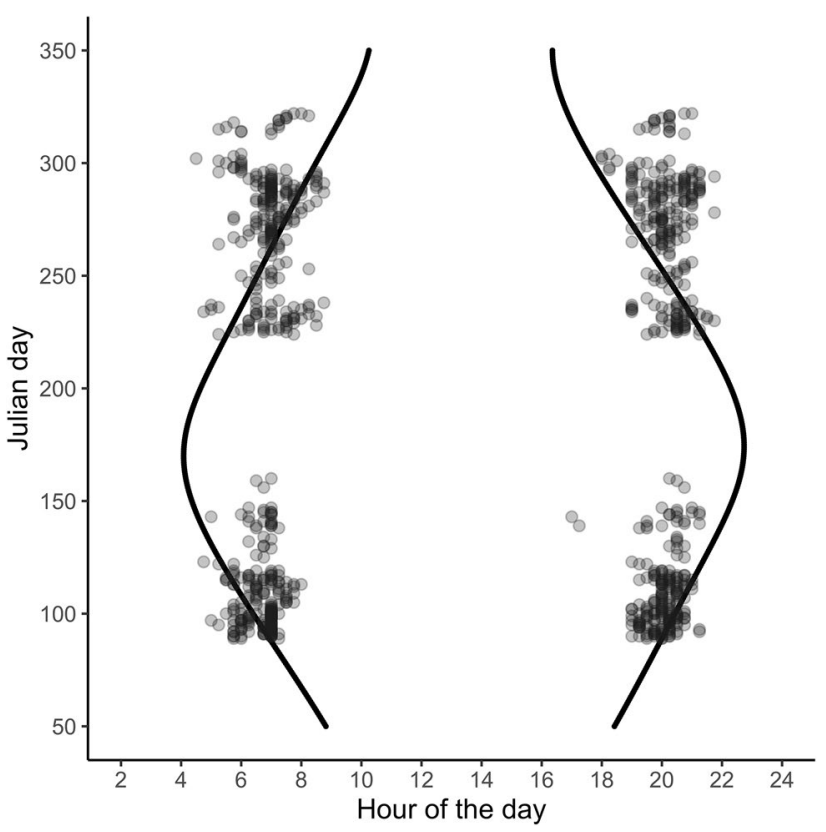

Fig. 1 Relationship between the time of sunrise (left black line) and sunset (right black line) each day of the year (Julian days) and the beaver activity start (right dots) and end (left dots) of 47 GPS-tagged Eurasian beavers (Castor fiber) in south-eastern Norway $(N=418)$

when the days were shorter (early spring and late fall), whereas the reverse was the case during longer days (Fig. 1).

On average, beavers were active for 9:42 $\pm 1: 37 \mathrm{~h}$ (range; 3:15-12 h) per night. The activity period was best explained by age and precipitation (Fig. 2). Activity period decreased with increasing age $(\beta=-0.348, \mathrm{SE}=0.132$, 95\% CI: $-0.607,-0.089)$, and increased with increasing precipitation $(\beta=0.124, \mathrm{SE}=0.053,95 \%$ CI: $0.020,0.227)$. Sex, Julian day, temperature and moon illumination were uninformative. The variance between individuals was of $1.092 \pm 1.045$ (residuals: $\beta=1.057, \mathrm{SE}=1.028$ ).

On average, $52.2 \%(\mathrm{SD}=10.9)$ of an individual's GPS positions were located in water (range $29.1-81.1 \%$ ). 
Table 2 Number of observations $(N)$, estimate $(\beta)$, standard error (SE), lower (LCI) and upper (UCI) 95\% confidence intervals and pseudo $R$-squared [marginal ${ }^{\mathrm{a}}(\mathrm{m})$ and conditional ${ }^{\mathrm{b}}$ (c) coefficients] for the start and end times related to sunset and sunrise data separately for spring (March-June) and fall (August-October) for 47 Eurasian beavers (Castor fiber) equipped with a GPS between 2009 and 2016 in south-eastern Norway

\begin{tabular}{llrrrrr}
\hline Model & $N$ & $\beta$ & SE & LCI & UCI & $R^{2}{ }_{\mathrm{m}}$ \\
\hline Spring & & & & & & $R^{2}{ }_{\mathrm{c}}$ \\
Start & 191 & 0.130 & 0.022 & 0.087 & 0.174 & 0.450 \\
End & & -0.169 & 0.017 & -0.204 & -0.134 & 0.607 \\
Fall & & & & & 0.738 \\
Start & 227 & -0.481 & 0.036 & -0.559 & -0.411 & 0.770 \\
End & & 0.370 & 0.046 & 0.271 & 0.460 & 0.557 \\
\hline
\end{tabular}

${ }^{a}$ The marginal $R$-squared coefficient describes the proportion of variance explained by the fixed effects alone

${ }^{\mathrm{b}}$ The conditional $R$-squared coefficient describes the proportion of variance explained by both the fixed and the dependent variable
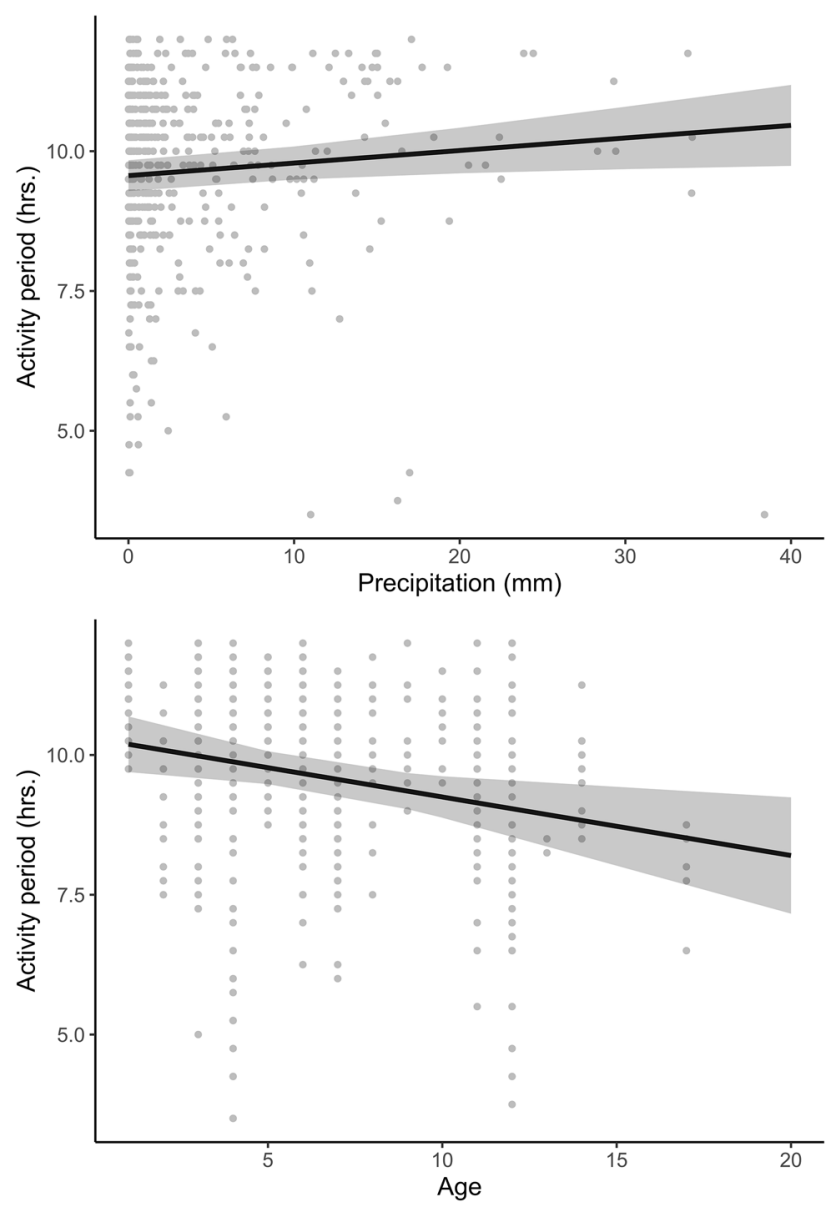

Fig. 2 The effect of precipitation (top) and age (bottom) on the activity period of 47 GPS-tagged Eurasian beavers (Castor fiber) in southeastern Norway $(N=658)$. The solid line represents the estimate and the grey shading the lower and upper $95 \%$ confidence interval. Grey dots represent raw data, and dot size indicates the number of observations

Beavers spent less time in the water with increasing age and precipitation, and spent more time in the water with increasing moon illumination (Table 3 ). Further, individuals tended to spend more time in the water during the summer days (June and August) compared to spring and fall (quadratic term of Julian day, but not the linear term, was informative). Temperature, sex, and social status were uninformative (Table 3).

Beavers moved on average $134 \pm 50 \mathrm{~m} / 15$ min per night (range: 4-596 m/15 min per night) and an average of $3.499 \pm 2043 \mathrm{~m}$ per night (range: $82-10.948 \mathrm{~m}$ per night). Distance moved was shorter during the later days of the year (fall), compared to the spring days, and within these two periods, the distance moved was longer during the summer (June and August) compared to early spring and late fall (Table 3). Also, beavers travelled greater distances with increasing moonlight and temperature, and when they were younger (Table 3, Fig. 3).

\section{Discussion}

As hypothesised, beavers appeared to adjust their activity and movement patterns to environmental factors such as moonlight conditions (I), air temperature (II) and precipitation (III), and some of the variation in activity and movement could be attributed to the age of the individuals (IV). In general, our models explained relatively little of the variation in activity time and movement patterns (proportion of time spent in water and average distance moved per night), with seasonal changes and age having a larger effect than moon illumination and weather, as shown in other studies (Mayer et al. 2019b). This is plausible from a biological perspective, as activity and movement are likely predominantly driven by energetic requirements and other biological factors, such as territory defence (Mayer et al. 2019a), forcing individuals to forage and patrol their territory also during bright hours and suboptimal weather conditions.

At northern latitudes, the months between late fall and early spring have characteristically long nights, which might explain why beavers were not active during the 
Table 3 Model-averaged estimate $(\beta)$, standard error (SE), lower (LCI) and upper (UCI) 95\% confidence interval and random effects variance and standard deviation (SD) for the analysis of (1) proportion of time spent in water and (2) average distance moved ( $\mathrm{m} / \mathrm{burst})$ for 18,652 GPS positions of 47 Eurasian beavers (Castor fiber) equipped with a GPS between 2009 and 2016 in south-eastern Norway

\begin{tabular}{|c|c|c|c|c|}
\hline Fixed effects & $B$ & SE & LCI & UCI \\
\hline \multicolumn{5}{|c|}{ (1) Proportion of time spent in water } \\
\hline \multicolumn{5}{|l|}{$N=658$} \\
\hline Age & -0.141 & 0.053 & -0.244 & -0.037 \\
\hline Moon illumination & 0.078 & $\mathbf{0 . 0 2 2}$ & 0.034 & 0.122 \\
\hline Julian day & 0.054 & 0.070 & -0.029 & 0.23 \\
\hline Julian day $^{2}$ & -0.195 & 0.103 & -0.394 & -0.009 \\
\hline Precipitation & 0.017 & 0.019 & -0.006 & 0.190 \\
\hline Sex (male) & 0.055 & 0.060 & -0.017 & 0.190 \\
\hline Temperature & -0.013 & 0.025 & -0.097 & 0.026 \\
\hline Status (subordinate) & 0.000 & 0.022 & -0.165 & 0.170 \\
\hline Random effects & Variance & SD & & \\
\hline Beaver ID & 0.160 & 0.399 & & \\
\hline \multicolumn{5}{|c|}{$\begin{array}{l}\text { (2) Average distance moved }(\mathrm{m} / 15 \mathrm{~min}) \\
(N=695)\end{array}$} \\
\hline Age & -9.469 & 4.085 & -17.482 & -1.456 \\
\hline Moon illumination & 6.804 & 1.489 & 3.884 & 9.723 \\
\hline Julian day & -12.378 & 4.213 & -20.641 & -4.11 \\
\hline Julian day $^{2}$ & -13.808 & 6.789 & -27.125 & -0.491 \\
\hline Precipitation & 1.045 & 1.069 & -1.052 & 3.141 \\
\hline Temperature & 5.485 & 2.089 & 1.387 & 9.583 \\
\hline Status (subordinate) & -13.645 & 12.183 & -37.544 & 10.253 \\
\hline Sex (male) & 8.211 & 7.631 & -6.758 & 23.179 \\
\hline Random effects & Variance & SD & & \\
\hline Beaver ID & 855.1 & 29.24 & & \\
\hline Residuals & 1457.4 & 38.18 & & \\
\hline
\end{tabular}

Informative variables are in bold

entire dark period of the night (contrary to prediction I.a.). In contrast, summer days are very long at northern latitudes (almost $19 \mathrm{~h}$ of daylight in our study area around summer solstice, and no real darkness), so the animals also need to be active during bright hours to meet their biological needs, e.g. foraging and territory defence, and to maximize energy intake as shown in other species (Brivio et al. 2017; Dunbar et al. 2009; Loe et al. 2007).

We probably underestimated the activity time to some degree, because it is likely that beavers were sometimes active before 19:00 $\mathrm{h}$ and after 07:00 $\mathrm{h}$ (Swinnen et al. 2015). The average start of beaver activity was after 20:00 h, making it unlikely that beavers regularly started before 19:00 h. However, the mean end of beaver activity was at $6: 39 \mathrm{~h}$ and 6:59 $\mathrm{h}$ in spring and fall, respectively, which makes it likely that the true activity ended somewhat later. Based on visual observations, however, Sharpe and Rosell (2003) reported the average end of activity between 4:38 and 06:03 $\mathrm{h}$ in the same study population, suggesting that not much information is lost by programming GPS units to end at 07:00 h.

Beavers spent more time in water with increasing moonlight, consequently leading to an increased distance moved (because beavers move greater distances in water; predictions I.b. and I.c.), which might indicate anti-predator behaviour. Hunting was the reason for about $20 \%$ of all observed mate changes in our study area (Mayer et al. 2017a), and beavers in our study area show an innate response to natural predators (Rosell and Sanda 2006). In Scandinavia, hunting with firearms is the predominant harvest type, with the majority of individuals killed on land (Parker et al. 2002). In Voyageurs National Park, a study reported that North American beavers were usually predated by wolf on land (Gable et al. 2016). Moreover, the eyesight of beavers, when in low light conditions, is poor, as they are lacking a tapetum lucidum (Hut et al. 2012; Rodriguez-Ramos Fernandez and Dubielzig 2013), which can potentially give them a disadvantage in detecting a predator before being detected [the tapetum lucidum is present in Eurasian lynx (Maffei et al. 1990) and wolves (Ollivier et al. 2004)]. In support of this, wolf predation increased with moon illumination due to more prey availability and easier visual detection of prey (Theuerkauf et al. 2003). Therefore, the adjustment on activity and space use is likely an adaptation to hunting and predation pressures, and beavers might spend more time on land (where it is more difficult for them to escape) on darker nights, as predator and hunter activity are reduced, leading to decreased predation risk.

Beavers moved greater distances with warmer temperatures (prediction II.a.), yet the temperature was not informative for the activity length and the time spent in water (II.b.). Although temperature showed no effect on the position selected by the beavers (being in water or on land), compared between spring and fall, beavers tended to spend more time in the water during the summer, when temperatures tended to be warmer (June and August were the months with the highest temperatures), and likely resulted in the observed increase in distance moved. This is in accordance with previous findings that suggest that beavers optimize daily energy costs and reduce the time spent in water during colder periods to reduce the loss of body heat (MacArthur and Dyck 1990; Nolet and Rosell 1994).

As predicted, beavers were active for longer periods of time (prediction III.a.) and spent more time on land than in water (III.b.) with increasing precipitation. This might be a response to reduced predation risk, provided that hunters and predators hunt less or are less efficient when rainfall is heavier, as the falling rain dampens sounds (Vickery and Bider 1981) and reduces the olfactory ability of predators and hence prey detection (Conover 2007; Syrotuck 2000). For example, oldfield mice (Peromyscus polionotus) increased 
Fig. 3 The effect of Julian day (quadratic effect; top), moon illumination (centre, $0=$ no illumination, $1=$ full moon), and medium temperature (bottom) on the average distance moved (m/15 min/night) of 47 GPS-tagged Eurasian beavers (Castor fiber) in south-eastern Norway $(N=695)$. The solid line represents the estimate and the grey shading the lower and upper $95 \%$ confidence interval. Grey dots represent the raw data

activity during rainy days, suggesting that they use indirect cues such as rainfall to anticipate predation risk (Orrock et al. 2004). Also, rainfall might alter the scents in both the substrate and the air, by washing away the smells with strong precipitation, or by releasing smell particles with the wet soil from little rain (Rosell 2018). The use of predator scent enables animals to assess predation risk, and, therefore, to behave or move according to it (Campbell-Palmer and Rosell 2011). North American beavers avoided foraging in spots with predator odours, suggesting that beavers use olfactory cues to detect predators (Salandre et al. 2017; Severud et al. 2011), even if predators are not actually present in the area (Salandre et al. 2017). Therefore, beavers appear to be unable to sense the presence of predators during high precipitation, because predator scent might be washed away. As a consequence, beavers may increase their foraging activities on land during periods with heavier precipitation.

Younger beavers were active for longer periods of time (prediction IV.a.), moved greater distances (IV.b.) and spent more time in water (IV.c.) than older beavers. This is in line with previous studies, who found that beavers adjust spatial movement patterns with age (Graf et al. 2016), either due to increased experience or senescence, which are not mutually exclusive. Another explanation would be that age was related to dominance, which has been suggested in moose (Alces alces), which showed a positive relationship between home-range size and age (Cederlund and Sand 1994). However, this was only true for males, so it would not fit for beavers, as both male and female exhibit a similar use of the territory (Herr and Rosell 2004). Moreover, sex was uninformative in our study. This fits other studies that showed no significant sex-related effect on movement patterns of beavers, probably because both sexes share parental care and scent marking behaviour (Herr and Rosell 2004; Sharpe and Rosell 2003). Both sexes of muskrats (Ondatra zibethicus), also a monogamous semiaquatic mammal, exhibit similar movement behaviour (Marinelli and Messier 1993). Social status might have an effect on behaviour; however, we did not identify that in our study.

\section{Conclusion}

Our study adds to the increasing amount of evidence that animal behaviour is modulated by various endogenous and exogenous factors, and that weather conditions can play a
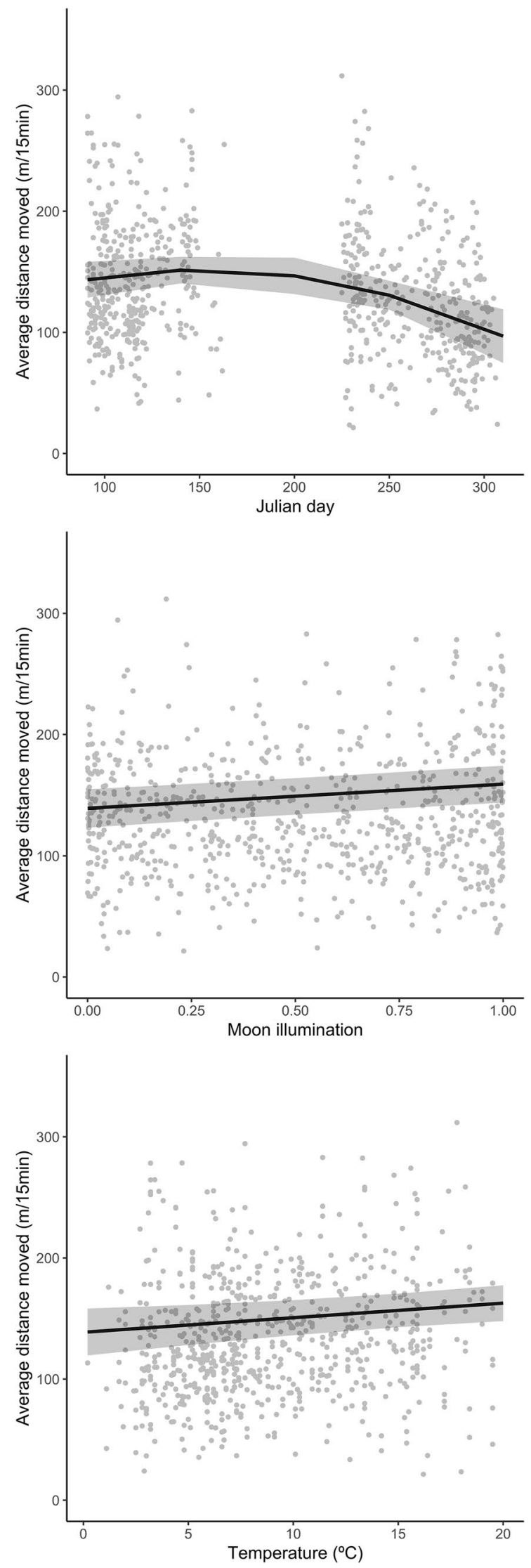
role in their behaviour (albeit to a lesser extent in our study). Under the predicted climate change scenarios (Coumou and Rahmstorf 2012), weather variability is expected to be most pronounced at northern latitudes (Trenberth et al. 2007). This implies that it may become increasingly challenging for high latitude species to anticipate on either condition to fulfil their primary needs and how that interplays with, for example, predation risk. It remains to be tested how increasingly variable weather and climate, together with hunting and predation pressure and habitat change affects space use, life-history parameters and demography in species such as the Eurasian beaver.

Acknowledgements Open Access funding provided by University Of South-Eastern Norway. We thank Christian A. Robstad, Manuel Echeverria, Anders Mydland, Patricia M. Graf, Julia Hochreiter, Richard Gunner, Fabian Künzel, Elena Pi Serra and Kathrin Hohwieler for assistance in the field, and Shane Frank for statistical advice. This study was funded by the University of South-Eastern Norway.

Open Access This article is licensed under a Creative Commons Attribution 4.0 International License, which permits use, sharing, adaptation, distribution and reproduction in any medium or format, as long as you give appropriate credit to the original author(s) and the source, provide a link to the Creative Commons licence, and indicate if changes were made. The images or other third party material in this article are included in the article's Creative Commons licence, unless indicated otherwise in a credit line to the material. If material is not included in the article's Creative Commons licence and your intended use is not permitted by statutory regulation or exceeds the permitted use, you will need to obtain permission directly from the copyright holder. To view a copy of this licence, visit http://creativecommons.org/licenses/by/4.0/.

\section{References}

Anderson DR (2007) Model based inference in the life sciences: a primer on evidence. Springer, New York

Arnold TW (2010) Uninformative parameters and model selection using Akaike's information criterion. J Wildl Manag $74: 1175-1178$

Baker JD, Antonelis GA, Fowler CW, York AE (1995) Natal site fidelity in northern fur seals, Callorhinus ursinus. Anim Behav 50:237-247

Bartness TJ, Albers HE (2000) Activity patterns and the biological clock in mammals, activity patterns in small mammals. Springer, New York, pp 23-47

Bates D, Maechler M, Bolker B, Walker S (2015) Fitting linear mixedeffects models using lme4. J Stat Softw 67(1):1-48

Bradt GW (1938) A study of beaver colonies in Michigan. J Mammal 19:139-162

Brivio F, Grignolio S, Brogi R, Benazzi M, Bertolucci C, Apollonio M (2017) An analysis of intrinsic and extrinsic factors affecting the activity of a nocturnal species: the wild boar. Mammal Biol Z Säugetierkd 84:73-81

Brown JS, Kotler BP (2004) Hazardous duty pay and the foraging cost of predation. Ecol Lett 7:999-1014

Burles D, Brigham R, Ring R, Reimchen T (2009) Influence of weather on two insectivorous bats in a temperate Pacific Northwest rainforest. Can J Zool 87:132-138
Burnham KP, Anderson DR, Huyvaert KP (2011) AIC model selection and multimodel inference in behavioral ecology: some background, observations, and comparisons. Behav Ecol Sociobiol 65:23-35

Campbell RD, Newman C, Macdonald DW, Rosell F (2013) Proximate weather patterns and spring green-up phenology effect Eurasian beaver (Castor fiber) body mass and reproductive success: the implications of climate change and topography. Glob Change Biol 19:1311-1324

Campbell RD, Nouvellet P, Newman C, Macdonald DW, Rosell F (2012) The influence of mean climate trends and climate variance on beaver survival and recruitment dynamics. Glob Change Biol 18:2730-2742

Campbell RD, Rosell F, Nolet BA, Dijkstra VA (2005) Territory and group sizes in Eurasian beavers (Castor fiber): echoes of settlement and reproduction? Behav Ecol Sociobiol 58:597-607

Campbell-Palmer R, Rosell F (2011) The importance of chemical communication studies to mammalian conservation biology: a review. Biol Cons 144:1919-1930

Caraco T, Blanckenhorn WU, Gregory GM, Newman JA, Recer GM, Zwicker SM (1990) Risk-sensitivity: ambient temperature affects foraging choice. Anim Behav 39:338-345

Cederlund G, Sand H (1994) Home-range size in relation to age and sex in moose. J Mammal 75:1005-1012

Conover MR (2007) Predator-prey dynamics: the role of olfaction. CRC Press, London

Coumou D, Rahmstorf S (2012) A decade of weather extremes. Nat Clim Change 2:491

Daly M, Behrends PR, Wilson MI, Jacobs LF (1992) Behavioural modulation of predation risk: moonlight avoidance and crepuscular compensation in a nocturnal desert rodent, Dipodomys merriami. Anim Behav 44:1-9

DunbarKorstjens RIAH, Lehmann J, Project, B.A.C.R. (2009) Time as an ecological constraint. Biol Rev 84:413-429

Fernandez-Duque E (2003) Influences of moonlight, ambient temperature, and food availability on the diurnal and nocturnal activity of owl monkeys (Aotus azarai). Behav Ecol Sociobiol 54:431-440

Gable TD, Windels SK, Bruggink JG, Homkes AT (2016) Where and how wolves (Canis lupus) kill beavers (Castor canadensis). PLoS ONE 11:e0165537

Gaynor KM, Hojnowski CE, Carter NH, Brashares JS (2018) The influence of human disturbance on wildlife nocturnality. Science 360:1232-1235

Graf P, Mayer M, Zedrosser A, Hackländer K, Rosell F (2016) Territory size and age explain movement patterns in the Eurasian beaver. Mammal Biol Z Säugetierkd 81:587-594

Haarberg O, Rosell F (2006) Selective foraging on woody plant species by the Eurasian beaver (Castor fiber) in Telemark, Norway. J Zool 270:201-208

Hartman G, Törnlöv S (2006) Influence of watercourse depth and width on dam-building behaviour by Eurasian beaver (Castor fiber). J Zool 268:127-131

Herr J, Rosell F (2004) Use of space and movement patterns in monogamous adult Eurasian beavers (Castor fiber). J Zool 262:257-264

Hertel AG, Zedrosser A, Mysterud A, Støen O-G, Steyaert SM, Swenson JE (2016) Temporal effects of hunting on foraging behavior of an apex predator: do bears forego foraging when risk is high? Oecologia 182:1019-1029

Hill R, Barrett L, Gaynor D, Weingrill T, Dixon P, Payne H, Henzi S (2003) Day length, latitude and behavioural (in) flexibility in baboons (Papio cynocephalus ursinus). Behav Ecol Sociobiol 53:278-286

Huck M, Juárez CP, Fernández-Duque E (2017) Relationship between moonlight and nightly activity patterns of the ocelot (Leopardus 
pardalis) and some of its prey species in Formosa, Northern Argentina. Mammal Biol Z Säugetierkd 82:57-64

Hut RA, Kronfeld-Schor N, van der Vinne V, De la Iglesia H (2012) In search of a temporal niche: environmental factors. In: Progress in brain research. Elsevier, London, pp 281-304

Ingram DK (2000) Age-related decline in physical activity: generalization to nonhumans. Med Sci Sports Exerc 32:1623-1629

Julien-Laferrière D (1997) The influence of moonlight on activity of woolly opossums (Caluromys philander). J Mammal 78:251-255

Kaczensky P, Huber D, Knauer F, Roth H, Wagner A, Kusak J (2006) Activity patterns of brown bears (Ursus arctos) in Slovenia and Croatia. J Zool 269:474-485

Kelley D, Richards C (2019) oce: analysis of oceanographic data. R package version 1.1-1

Kile NB, Nakken PJ, Rosell F, Espeland S (1996) Red fox, Vulpes vulpes, kills a European beaver, Castor fiber, kit. Can Field Nat 110:338-339

Kleiman DG (1977) Monogamy in mammals. Q Rev Biol 39-69

Lancia RA, Dodge WE, Larson JS (1982) Winter activity patterns of two radio-marked beaver colonies. J Mammal 63:598-606

Loe LE, Bonenfant C, Mysterud A, Severinsen T, Øritsland NA, Langvatn R, Stien A, Irvine RJ, Stenseth NC (2007) Activity pattern of arctic reindeer in a predator-free environment: no need to keep a daily rhythm. Oecologia 152:617-624

MacArthur RA (1989) Energy metabolism and thermoregulation of beaver (Castor canadensis). Can J Zool 67:651-657

MacArthur RA, Dyck AP (1990) Aquatic thermoregulation of captive and free-ranging beavers (Castor canadensis). Can J Zool 68:2409-2416

Maffei L, Fiorentini A, Bisti S (1990) The visual acuity of the lynx. Vis Res 30:527-528

Marinelli L, Messier F (1993) Space use and the social system of muskrats. Can J Zool 71:869-875

Martin LE, Byrne AW, O'Keeffe J, Miller MA, Olea-Popelka FJ (2017) Weather influences trapping success for tuberculosis management in European badgers (Meles meles). Eur J Wildl Res 63:30

Mayer M (2017) Territoriality and life history strategies of the Eurasian beaver. PhD thesis, University of South-Eastern Norway

Mayer M, Frank S, Zedrosser A, Rosell F (2019a) Causes and consequences of inverse density-dependent territorial behavior and aggression in a monogamous mammal. J Anim Ecol

Mayer M, Künzel F, Zedrosser A, Rosell F (2017) The 7-year itch: non-adaptive mate change in the Eurasian beaver. Behav Ecol Sociobiol 71:32

Mayer M, Ullmann W, Heinrich R, Fischer C, Blaum N, Sunde P (2019) Seasonal effects of habitat structure and weather on the habitat selection and home range size of a mammal in agricultural landscapes. Landscape Ecol 34:2279-2294

Mayer M, Zedrosser A, Rosell F (2017a) Extra-territorial movements differ between territory holders and subordinates in a large, monogamous rodent. Sci Rep 7:15261

Mayer M, Zedrosser A, Rosell F (2017b) When to leave: the timing of natal dispersal in a large, monogamous rodent, the Eurasian beaver. Anim Behav 123:375-382

Mott CL, Bloomquist CK, Nielsen CK (2011) Seasonal, diel, and ontogenetic patterns of within-den behavior in beavers (Castor canadensis). Mammal Biol Z Säugetierkd 76:436-444

Müller-Schwarze D, Schulte BA (1999) Behavioral and ecological characteristics of a "climax" population of beaver (Castor canadensis), Beaver protection, management, and utilization in Europe and North America. Springer, New York, pp 161-177

MuMIn BK (2013) Multi-model inference. R package version 1.9.13

Nathan R, Getz WM, Revilla E, Holyoak M, Kadmon R, Saltz D, Smouse PE (2008) A movement ecology paradigm for unifying organismal movement research. Proc Natl Acad Sci 105:19052-19059
Nolet BA, Rosell F (1994) Territoriality and time budgets in beavers during sequential settlement. Can J Zool 72:1227-1237

Norwegian Mapping Authority (Kartverket) (2017)

Norwegian Meteorological Institute (MET) (2017)

Ollivier F, Samuelson D, Brooks D, Lewis P, Kallberg M, Komáromy A (2004) Comparative morphology of the tapetum lucidum (among selected species). Vet Ophthalmol 7:11-22

Orrock JL, Danielson BJ, Brinkerhoff RJ (2004) Rodent foraging is affected by indirect, but not by direct, cues of predation risk. Behav Ecol 15:433-437

Parker H, Rosell F, Hermansen TA, Sørløkk G, Stærk M (2002) Sex and age composition of spring-hunted Eurasian beaver in Norway. J Wildl Manag 1164-1170

R Core Team (2013) R: a language and environment for statistical computing. R Foundation for Statistical Computing, Vienna

Rodriguez-Ramos Fernandez J, Dubielzig RR (2013) Ocular comparative anatomy of the family Rodentia. Vet Ophthalmol 16:94-99

Rosell F (2018) Secrets of the snout: the dog's incredible nose. University of Chicago Press, Chicago

Rosell F, Hovde B (2001) Methods of aquatic and terrestrial netting to capture Eurasian beavers. Wildl Soc Bull 29:269-274

Rosell F, Nolet BA (1997) Factors affecting scent-marking behavior in Eurasian beaver (Castor fiber). J Chem Ecol 23:673-689

Rosell F, Parker H (1995) Forvaltning av bever: dagens tilstand og fremtidig behov.(In Norwegian with English summary: Beaver management: present practice and Norway's future needs.). Report Telemark College, B $\emptyset$ in Telemark Norway

Rosell F, Parker H, Steifetten $\emptyset$ (2006) Use of dawn and dusk sight observations to determine colony size and family composition in Eurasian beaver Castor fiber. Acta Theriol 51:107-112

Rosell F, Sanda J (2006) Potential risks of olfactory signaling: the effect of predators on scent marking by beavers. Behav Ecol 17:897-904

Rosell F, Sun L (1999) Use of anal gland secretion to distinguish the two beaver species Castor canadensis and C. fiber. Wildl Biol $5: 119-123$

Rosell F, Zedrosser A, Parker H (2010) Correlates of body measurements and age in Eurasian beaver from Norway. Eur J Wildl Res 56:43-48

Salandre JA, Beil R, Loehr JA, Sundell J (2017) Foraging decisions of North American beaver (Castor canadensis) are shaped by energy constraints and predation risk. Mammal Res 62:229-239

Schlippe Justicia L, Rosell F, Mayer M (2018) Performance of GPS units for deployment on semiaquatic animals. PLoS ONE 13:e0207938

Sefick Jr SA (2016) Stream metabolism-A package for calculating single station metabolism from diurnal oxygen curves $\mathrm{R}$ package version 1.1.2

Severud WJ, Belant JL, Bruggink JG, Windels SK (2011) Predator cues reduce American beaver use of foraging trails. Hum-Wildl Interact 5:296-305

Sharpe F, Rosell F (2003) Time budgets and sex differences in the Eurasian beaver. Anim Behav 66:1059-1067

Sikes RS, Care A, Mammalogists, U.C.o.t.A.S.o. (2016) 2016 Guidelines of the American Society of Mammalogists for the use of wild mammals in research and education. J Mammal 97:663-688

Steen I, Steen J (1965) Thermoregulatory importance of the Beaver's tail. Comp Biochem Physiol 15:267-270

Steyaert SM, Swenson JE, Zedrosser A (2014) Litter loss triggers estrus in a nonsocial seasonal breeder. Ecol Evol 4:300-310

Steyaert SM, Zedrosser A, Rosell F (2015) Socio-ecological features other than sex affect habitat selection in the socially obligate monogamous Eurasian beaver. Oecologia 179:1023-1032

Stokes MK, Slade NA, Blair SM (2001) Influences of weather and moonlight on activity patterns of small mammals: a biogeographical perspective. Can J Zool 79:966-972 
Svendsen GE (1980) Seasonal change in feeding patterns of beaver in southeastern Ohio. J Wildl Manag 285-290

Swinnen KR, Hughes NK, Leirs H (2015) Beaver (Castor fiber) activity patterns in a predator-free landscape. What is keeping them in the dark? Mammal Biol Z Säugetierkd 80:477-483

Syrotuck WG (2000) Scent and the scenting dog. Barkleigh Productions, Inc, Mechanicsburg

Tevis L (1950) Summer behavior of a family of beavers in New York State. J Mammal 31:40-65

Theuerkauf J, Jẹdrzejewski W, Schmidt K, Okarma H, Ruczyński I, Śniezko S, Gula R (2003) Daily patterns and duration of wolf activity in the Białowieza Forest, Poland. J Mammal 84:243-253

Thompson P, Fedak M, McConnell B, Nicholas K (1989) Seasonal and sex-related variation in the activity patterns of common seals (Phoca vitulina). J Appl Ecol 521-535

Togunov RR, Derocher AE, Lunn NJ (2017) Windscapes and olfactory foraging in a large carnivore. Sci Rep 7:46332

Trenberth K, Jones P, Ambenje P, Bojariu R, Easterling D, Klein Tank A, Parker D, Rahimzadeh F, Renwick J, Rusticucci M (2007) Observations: surface and atmospheric climate change. Chapter 3. Climate change, pp 235-336
Vickery W, Bider J (1981) The influence of weather on rodent activity. J Mammal 62:140-145

Vieira AB, Melo R, Santos GB, Bazzoli N (2009) Reproductive biology of the peacock bass Cichla piquiti (Perciformes: Cichlidae), an exotic species in a Neotropical reservoir. Neotropical Ichthyol $7: 745-750$

Wilsson L (1971) Observations and experiments on the ethology of the European beaver (Castor fiber L.): a study in the development of phylogenetically adapted behaviour in a highly specialized mammal. Sven Jägareförbundet

Zuur AF, Ieno EN, Elphick CS (2010) A protocol for data exploration to avoid common statistical problems. Methods Ecol Evol 1:3-14

Publisher's Note Springer Nature remains neutral with regard to jurisdictional claims in published maps and institutional affiliations. 